\title{
Divided When Crisis Comes: How Perceived Self-Partner Disagreements over COVID-19 Prevention Measures Relate to Employee Work Outcomes at Home
}

\author{
Mingyun Huai ${ }^{1}$ Danyang Du$^{1}{ }^{10} \cdot$ Meng Chen ${ }^{1} \cdot$ Jian Liang ${ }^{1}$ \\ Accepted: 31 October 2021 \\ (c) The Author(s), under exclusive licence to Springer Science+Business Media, LLC, part of Springer Nature 2021
}

\begin{abstract}
As a response to the COVID-19 pandemic, our societies went into a lockdown model and many organizations required or permitted their employees to work from home. As a result, employees need to deal with the COVID-19 pandemic while they work from home, providing an opportunity to examine how COVID-19 prevention experiences influence those who are working from home. Based on the interpersonal self-regulation perspective, we propose that employees who perceive having more disagreements with their partners over COVID-19 prevention measures are more likely to experience a reduction in their identification with the partner which is subsequently associated with their negative work outcomes through emotional exhaustion. Results from a two-wave survey study with a sample of 282 employees who worked from home during the COVID-19 pandemic supported our predictions: perceived self-partner disagreements over COVID-19 prevention measures related to a reduction in identification with the partner, which was subsequently associated with exhausted regulatory resources and undermined work outcomes. Furthermore, these negative effects were particularly salient for individuals who were not married. Theoretical and practical implications for family-to-work interference and working from home in times of crisis are discussed.
\end{abstract}

Keywords Disagreements over COVID-19 prevention measures $\cdot$ Family-to-work interference $\cdot$ Identification with the partner $\cdot$ Emotional exhaustion $\cdot$ Work outcomes

The far-reaching COVID-19 pandemic reminds us that we inhabit a world with increasing disruptions and turbulence. In the midst of such a stressful crisis, individuals often feel incapable of grasping the world and of dealing with what is happening around them (Skoufias, 2003). They often see family as a major source of support to get through difficult times. However, a crisis can get 'inside the family' if the family unit cannot deal with the crisis effectively (Browne

Danyang Du

ddu@tongji.edu.cn

Mingyun Huai

myhuai@tongji.edu.cn

Meng Chen

mchen@tongji.edu.cn

Jian Liang

jianliang@tongji.edu.cn

1 Advanced Institute of Business, Tongji University, Siping Road, Shanghai 1500, China et al., 2015: 398). Negative family experiences may easily spill over to the work domain especially when work-family boundary becomes blurred (Barley et al., 2017). Therefore, it is valuable to incorporate crisis events into the discussion of the work-family interface and examine how negative family experiences in the context of crisis events produce spillover effects on employee work outcomes when employees work from home in the time of the COVID-19 pandemic (Eby et al., 2016).

Existing literature has generally analyzed family experiences in times of crisis, without extending the analysis to the work domain (MacDermid Wadsworth, 2010; Riggs \& Riggs, 2011; Valentine \& Hughes, 2010). Within the family domain, researchers have found that crisis has the potential to generate positive outcomes for family members, such as improvements in cohesion, resilience, communication, and intimacy (Eby et al., 2016). However, there is also a possibility that crisis may elicit fundamental differences between partners and even lead to relationship dissolution (Amato \& Rogers, 1997; Dew et al., 2012; Neppl et al., 2016). Paying 
attention to this possibility of "crisis coming into the family" is particularly important because of the greater power of negative experiences over positive ones (Baumeister, Bratslavsky, Finkenauer, \& Vohs, 2001). Particularly, these negative family experiences in response to COVID-19 can spill over to the work domain and are associated with negative work outcomes when the boundaries between family and work become increasingly vague in times of crisis, especially for employees who work from home.

The ongoing COVID-19 crisis provides an opportunity to study the presence and extent of such a negative spillover (Cho, 2020; Kramer \& Kramer, 2020). Unlike many other public or social issues, the COVID-19 crisis affects or has the potential to affect everyone, and therefore everyone has been involved in dealing with this crisis. To prevent people from falling ill, many societies have implemented a lockdown, which has included most businesses adopting a work-from-home model for employees (Baert et al., 2020; Cho, 2020; Duffy, 2020; Dubey \& Tripathi, 2020). However, there have been considerable disagreements over whether we should sacrifice personal freedom and accept the social constraints imposed on us (Conway III et al., 2021; Van Bavel et al., 2020). Such disagreements, which reflect deep-seated value differences, can be found within a family unit, such as when self and his/her partner disagree over COVID-19 prevention measures, with the self more supporting prevention measures whereas the partner more against them or vice versa.

Based on the interpersonal self-regulation perspective (Finkel et al., 2016; Fitzsimons et al., 2015; Fitzsimons \& Finkel, 2010; Radcliffe \& Cassell, 2014), we propose that perceived self-partner disagreements over COVID-19 prevention measures is associated with reduced individuals' self-regulation resources (e.g., emotional exhaustion) as the fundamental value differences behind the disagreements could relate to a significant reduction in individuals' perceptions of identification or sense of "oneness" with their partners. The reduction in identification with partners can capture the interpersonal nature of the theory because it reflects the changes of relationships between the self and his/her partner (Bernstein et al., 2016), and emotional exhaustion can capture the self-regulation part of the theory because it reflects the degree of self-regulation resources that an individual has (Muraven \& Baumeister, 2000). Through the mechanisms of reduction in identification with partners and reduced self-regulation resources, the perceived self-partner disagreements over COVID-19 prevention measures will be further related to negative individuals' work outcomes. As individuals who are married are more dedicated to their relationships with partners and tend to resolve tension with partners through cooperative strategies, we propose that the associations between perceived self-partner disagreements over COVID-19 prevention measures and reduced identification with partners, emotional exhaustion, and negative work outcomes are weaker for individuals who are married. Our research model is presented in Fig. 1.

The present study makes contributions to three important areas. First, as a direct response to the call for illustrating how non-work crisis events influence the work-family interface (Eby et al., 2016), we suggest that perceived selfpartner disagreements over COVID-19 prevention measures play an important role in shaping family-to-work interference during the pandemic. Different from everyday conflicts between partners, perceived disagreements about whether we should accept social constraints reflect deep-seated value differences and thus may associate with profound changes in the relationship and one's self-regulation resources. In particular, drawing upon the interpersonal self-regulation perspective (Finkel et al., 2016; Fitzsimons et al., 2015), we introduce reduction in identification with the partner and self-regulatory resource depletion as mechanisms to investigate how perceived disagreements between partners are associated with the work domain outcomes.

Second, we extend previous literature on work-family interface (e.g., Beigi et al., 2017; Beigi et al., 2018) by taking a process view to elucidate not only whether family-towork interference happens, but also how such interference happens. Previous literature on work-family interface has used concepts like family-to-work conflict (e.g., Byron, 2005; Ford et al., 2007; Michel, Kotrba, Michelson, Clark, $\&$ Baltes, 2011) to indicate whether family-to-work interference happens. However, this approach hardly tells how this interference happens. Differently, we aim to reveal the possible mechanisms and processes behind the phenomenon of family-to-work interference and examine the negative relationships between perceived disagreements with partners over COVID-19 prevention measures (in the family domain) and work outcomes (in the work domain). Revealing these detailed processes helps better reduce family-towork interference.

Third, this research advances our understanding of the role of family-to-work interference in implementing

Fig. 1 Theoretical model

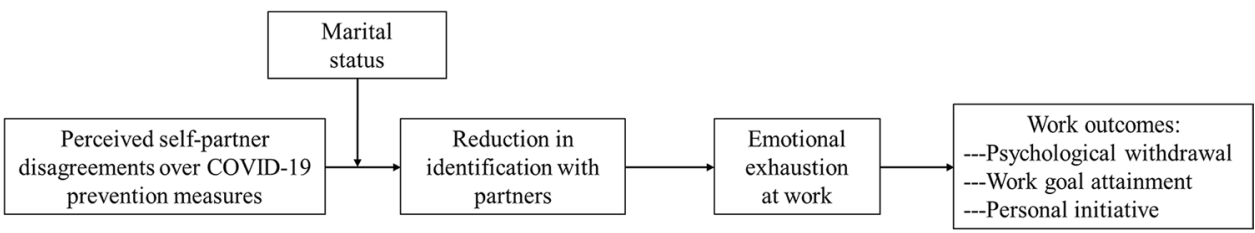


work-from-home policies. Working from home has recently become the subject of scholarly discussion, and evidence of its effectiveness has quickly accumulated (Allen et al., 2013; Bloom et al., 2015; Gajendran \& Harrison, 2007). However, researchers have warned that the effectiveness of such a policy may be threatened by family-to-work interference (Allen et al., 2013; Golden et al., 2006). As an extension to this strand of the literature, we demonstrate that perceived fundamental disagreements between partners can be one source of family-to-work interferences that jeopardizes the effectiveness of working from home.

\section{Theoretical Development and Hypotheses}

The COVID-19 global pandemic represents a serious crisis for human societies. To minimize the spread of the disease, governments are imposing extraordinarily restrictive measures that require people to stay at home and avoid going outside as much as possible (Thelwall \& Thelwall, 2020; Tian et al., 2020). Accordingly, many companies have permitted or required their employees to work from home, causing family and work lives of these employees more deeply intertwined. From the interpersonal self-regulation perspective (Fitzsimons et al., 2015), we speculate that if an individual perceives having high disagreements with the partner over COVID-19 prevention measures, he or she may experience the loss of self-regulation resources and further reduction of his or her work outcomes at home.

The interpersonal perspective on self-regulation posits that the relationships in which individuals are embedded play an important role in shaping their self-regulation processes (Finkel \& Fitzsimons, 2011; Fitzsimons \& Finkel, 2010). There is consistent evidence of relational factors influencing one's self-regulatory processes, such that negative interpersonal interactions tend to deplete self-regulatory resources and thus worsen personal goal achievements (Finkel et al., 2006). Therefore, this perspective is particularly helpful in understanding how individuals' perception of disagreements with their partner over COVID-19 prevention measures is related to their self-regulation in pursuing work goals when they work from home during the lockdown period.

\section{Perceived Self-Partner Disagreements and Self-Regulation Impairment: The Mechanism of Reduction in Identification with the Partner}

Many restrictive measures for preventing COVID-19, such as mandating the wearing of masks, avoiding of social gatherings, and tracing individuals' movements, have become highly contentious within societies, as such measures ask people to sacrifice personal freedom (Thelwall $\&$ Thelwall, 2020). While some people fully endorse and strictly obey such guidelines, others strongly resist because they believe that such regulations violate their human right of liberty and freedom (Van Bavel et al., 2020). When such disagreements emerge within a family between partners, fundamental differences in their attitudes to the value of human life and the inalienability of human rights might emerge, prompting them to reevaluate their relationship.

As two individuals in a romantic relationship get to know each other, their self-concepts usually become intertwined, and the psychological boundaries between them are blurred (Finkel et al., 2017). This process represents the development of identification-a perception of being oneness with another and a tendency to view the self as 'including [the] resources, perspectives, and characteristics of the other' (Aron et al., 1992: 598). However, the interconnection and oneness can be undone, manifesting in a reduction in identification, if significant differences are discovered between partners. As we highlighted, perceived disagreements over COVID-19 prevention measures between partners reflect a perception of mismatch in prioritizing personal freedom versus social constraint (Van Bavel et al., 2020). Discovery of such a mismatch alerts individuals to sharp differences from their partners in relation to the prioritizing and pursuing of human rights. As a consequence, identification with their partners is likely to decrease and they will feel a reduction in the sense of belonging and oneness within the relationship (Bernstein et al., 2016).

A fundamental aspect of close relationships is partners supporting and relying on each other in pursuing their goals (Finkel et al., 2016; Fitzsimons et al., 2015). However, they would hesitate to do so when losing feelings of togetherness with their partners (Feeney, 2007). Meanwhile, they are also more likely to experience negative interactions with their partners: for example, they may be easily provoked by certain words or behaviors of their partners that would otherwise not be perceived as provocative in periods of greater togetherness. As such negative interactions with their partners accumulate, individuals will experience unhappiness, animosity, frustration, and annoyance (Halevy et al., 2012), exhausting their resources. Integrating these arguments, we propose that:

Hypothesis 1: Perceived self-partner disagreements over COVID-19 prevention measures are positively related to a reduction in identification with the partner.

Hypothesis 2: Perceived self-partner disagreements over COVID-19 prevention measures are positively related to individuals' emotional exhaustion through reduction in identification with the partner. 


\section{Family-to-Work Interference: Negative Relations between Perceived Self-Partner Disagreements and Work Outcomes}

As emotional exhaustion links perceived self-partner disagreements over COVID-19 prevention measures and work domain experiences for those who are working from home by negative association with one's identification with the partner, it could further create a distraction and relate to negative outcomes, such as greater psychological withdrawal, less work goal attainment, and less demonstration of personal initiative. Psychological withdrawal from work includes the behaviors associated with tardiness or putting little effort into work tasks (Lehman \& Simpson, 1992). Work goal attainment refers to the extent to which employees can successfully achieve their work goals (Greguras \& Diefendorff, 2010). Personal initiative at work includes self-starting attempts to overcome barriers to achieve work goals and improve performance (Frese \& Fay, 2001). When employees work from home with less external supervision, they must regulate themselves more to perform at their jobs. When their resources are depleted, however, employees cannot mobilize enough resources into their work tasks. Thus, they are more likely to withdraw from their work (Chi \& Liang, 2013; Cole et al., 2010; Cropanzano et al., 2003), be less able to achieve work goals (Milyavskaya \& Inzlicht, 2017), and take less personal initiative in their work (Zacher et al., 2019).

Taken together, the above arguments suggest that perceived self-partner disagreements over COVID-19 prevention measures are likely to reduce identification with the partner by creating a sense of disunity between partners. Negative interactions associated with these disagreements will further relate to an individual's reduced self-regulation resources and impaired work outcomes. Therefore, we hypothesize that:

Hypothesis 3: Perceived self-partner disagreements over COVID-19 prevention measures are positively related to (a) psychological withdrawal, and negatively related to $(b)$ work goal attainment and (c) personal initiative, via a sequential path through reduction in identification with the partner and emotional exhaustion.

\section{Marital Status as a Moderator}

According to the interpersonal self-regulation perspective (Fitzsimons \& Finkel, 2010; Fitzsimons et al., 2015), when partners are dedicated to their relationships, they tend to resolve their tension through cooperative strategies and prevent tension and disagreements to damage their relationships and impair their self-regulation processes. Following this logic, we include individuals' marital status as a moderator because different marital status (e.g., being married versus not being married) reflects individuals' different levels of dedication and commitment to their relationships with their partners which shape their reactions to perceived disagreements with their partners over COVID-19 prevention measures.

For married individuals, performing daily activities with their spouses (e.g., addressing each other as wife or husband) makes their identity as a couple more salient (Stanley et al., 2002). Indeed, research has suggested that married people have a strong identity as a couple with their partners (Adams \& Jones, 1997) as they are dedicated and committed to their relationships with their partners, and their behaviors tend to be relationship oriented. Accordingly, married individuals will follow the social prescription of couple identity and show understanding and cooperation toward their partners (Sluss \& Ashforth, 2007). Thus, facing situations of disagreements over COVID-19 prevention measures, married couples are likely to try to compromise, share, and engage in creative cooperation (Duvall \& Hill, 1945). As such, the relationship between perceived disagreements and a reduction in identification is weaker for marrieds.

On the other hand, for couples who are not married, their couple identity is weaker than their married counterparts, even after controlling for length of relationship (Stanley et al., 2002). Quite the contrary, partners who are not married have higher levels of relationship independence, pursue more independent social networks, and preserve more individual identity than marrieds (Elizabeth, 2000). With a less strong sense of an identity as a couple and a stronger individual identity, these partners are less dedicated and committed to their relationships, and their behaviors are relatively less relationship oriented. Thus, facing situations of disagreements over COVID-19 prevention measures, unmarried partners are more likely to express their divergent opinions and behaviors (Jung \& Hecht, 2004) than to resort to cooperative strategies such as compromise to solve their disagreements and tensions. As such, the association between perceived disagreements and a reduction in identification is stronger for partners who are not married. Taken together, we hypothesize that:

Hypothesis 4: Marital status moderates the relationship between perceived self-partner disagreements over COVID-19 prevention measures and reduction in identification with the partner, such that the relationship is stronger for unmarried couples.

The integration of Hypotheses 3 and 4 suggests that the marital status plays a moderating role in the indirect 
relationships we have specified. Thus, we put forward the following hypothesis:

Hypothesis 5: Marital status moderates the indirect relationship between perceived self-partner disagreements over COVID-19 prevention measures and (a) psychological withdrawal, (b) work goal attainment, and (c) personal initiative via a sequential path through reduction in identification with the partner and emotional exhaustion, such that the indirect relationships are stronger for unmarried couples.

\section{Methods}

\section{Sample and Procedure}

We collected data through the online platform Prolific from participants located in the United Kingdom and United States where the outbreak and spread of COVID-19 pandemic shared a lot of similarities. The ongoing COVID-19 pandemic spread to the UK and US in January 2020 and, as the severity of the epidemic was recognized, the US government declared a national emergency on 13 March 2020 and the UK government imposed lockdown measures on 23 March 2020. Afterwards, many companies required their employees to work from home. To minimize the impact of common method bias on our results, we followed the recommendations of Podsakoff et al. (2003) and collected data with time separations between study variables. We started data collection in late April (Time 1) and asked participants to report perceived self-partner disagreements over COVID-19 prevention measures, identification with the partner before the outbreak of COVID-19, their marital status, and other demographic characteristics. One week later and in early May (Time 2), we asked participants to report identification with the partner after the outbreak of COVID-19, emotional exhaustion, and work outcomes in terms of psychological withdrawal, work goal attainment, and personal initiative.

A prior power analysis based on previous literature about the family interference with work (e.g., Amstad, Meier, Fasel, Elfering, \& Semmer, 2011) suggests that we need a sample size of 242 to arrive at a power of 0.95 . That being said, we increased our sample size due to possible sample loss during data collection. Particularly, we recruited 400 participants who were (a) in a romantic relationship, (b) working full-time, and (c) working from home due to COVID-19. As 79 participants did not pass our checks on these criteria, we deleted them from our analysis. Of the left participants, 321 completed the Time 1 survey (100\% response rate), and 282 completed the Time 2 survey ( $88 \%$ response rate). The final sample of 282 participants was over an ideal sample size of 242 and thus allowed us to achieve a good power of analysis. The final sample of 282 participants was on average 34.13 years old $(S D=8.39)$, with $57.8 \%$ female, and $49.6 \%$ married. $77.7 \%$ had a Bachelor's degree or above, and the average relationship duration with their partners was 8.84 years $(S D=7.27)$.

\section{Measures}

Items were scored on Likert scales anchored at 1 (strongly disagree) and 7 (strongly agree), unless otherwise specified.

Perceived self-partner disagreements over COVID-19 prevention measures Based on the international guidelines for preventing COVID-19 (World Health Organization, 2020), we selected nine restrictions that can capture an individual's attitudes about whether people should accept social constraints and sacrifice personal freedom. A sample item is, "To control the spread of COVID-19, people should stay home and avoid going outside as much as possible". Participants were asked to indicate the degree of consensus with their partners on these measures with an anchoring from $l$ $=$ we have low consensus to $7=$ we have high consensus. To capture the disagreements between partners, we reverse coded these items $(\alpha=0.79)$. Please check Appendix A for the full details on the scale.

Reduction in identification with the partner We used a pictorial measure (Aron et al., 1992) to assess the participants' oneness with their partners. Eight pictures were used to represent different degrees of overlap between the self and partner (see Appendix B). Participants were asked to choose the picture that best captured their feelings of togetherness with their partner at Time 1 (before the outbreak of COVID19) and at Time 2 (after the outbreak of COVID-19). The difference between the two scores was calculated to represent the level of reduction in identification with the partner (i.e., the more positive the value, the more the identification had decreased over time). The same form of measurements in a questionnaire may increase the possibility of common method variance in measurement (Podsakoff et al., 2003), and our pictorial measure may reduce this possibility. In addition, this pictorial approach has previously demonstrated sound psychometric properties (Shamir \& Kark, 2004; Schubert \& Otten, 2002; Swann et al., 2012).

Emotional exhaustion We used a 5-item scale (Pugh et al., 2011) to measure emotional exhaustion. The stem of the items is, "Since the outbreak of COVID-19, how often have you experienced the following feelings at your job?" and a sample item is "Being tired" ( $1=$ never, $7=$ always, $\alpha=$ $0.91)$. 
Work outcomes Participants were asked to indicate to what extent they agreed with the descriptions of their work behaviors since the outbreak of COVID-19. We used eight items from Lehman and Simpson (1992) to measure participants' levels of psychological withdrawal. A sample item is, "I put less effort into my job than I should have" $(1=$ never, $7=$ very often; $\alpha=0.78)$. We used four items from Greguras and Diefendorff (2010) to measure the participants' levels of work goal attainment. A sample item is, "I achieved what I wanted to achieve with my work goals" $(\alpha=0.94)$. We used a 7-item scale to measure the participants' levels of self-initiative in work behavior (Frese et al., 1997). A sample item is, "I did more than I was asked to do" $(\alpha=0.90)$.

Marital status We asked participants whether they were married with their partner with "I am not married with my partner" coded as 0 and "I am married with my partner" coded as 1 .

Control variables First, we controlled for the demographic characteristics of age and gender, considering their possible influences on family-to-work interference (Cunningham \& De La Rosa, 2008; Pleck, 1977; Westman, 2002). Second, partners who were married tended to have a longer relationship duration, but marital status is more than just longer relationship (Wang, Zhao, \& Lei, 2019). We therefore controlled for relationship duration with the partner to preclude its possible confounding influence on the effects of perceived disagreements. Finally, we controlled for identification with the partner before the COVID-19 outbreak to eliminate the influence of the starting value of identification with the partner on work outcomes.

\section{Results}

\section{Confirmative Factor Analysis (CFA)}

We conducted a series of CFAs to examine the distinctiveness of five study variables: perceived self-partner disagreements over COVID-19 prevention measures, emotional exhaustion, psychological withdrawal, work goal attainment, and personal initiative. To achieve an optimal ratio of values to sample size, we randomly created three parcels for perceived self-partner disagreements over COVID-19 prevention measures, psychological withdrawal, and personal initiative, each of which had seven or more items (Little et al., 2002). As shown in Table 1, the data fit the baseline fivefactor model (Model 1) well $\left(\chi^{2}(125)=242.91, p<.001\right.$, root-mean-square error of approximation $[\mathrm{RMSEA}]=.06$, comparative fit index $[\mathrm{CFI}]=.97$, Tucker-Lewis index $[\mathrm{TLI}]$ $=.96$, standardized root-mean-square residual [SRMR] $=$ .05 ), and better than the alternative models.

Following the procedures recommended by Podsakoff et al. (2003), we further added one uncorrelated latent method factor to Model 1 to examine the threat of common method variance to our study. The chi-square difference test showed that adding the uncorrelated method factor (Model 6) did not significantly improve the base-line model $\left(\Delta \chi^{2}=\right.$ $.74, d f=2, p=.69$ ), suggesting that common method variance was not a serious issue in the current study.

\section{Descriptive Statistics}

Table 2 displays the means, standard deviations, reliabilities of the variables, and the correlations among them.

Table 1 CFA results

\begin{tabular}{|c|c|c|c|c|c|c|}
\hline Models & $\chi^{2}(\mathrm{df})$ & $\Delta \chi^{2}(\Delta \mathrm{df})$ & RMSEA & CFI & TLI & SRMR \\
\hline 1. Five-factor baseline model ${ }^{\mathrm{a}}$ : & $242.91^{* *}(125)$ & & .06 & .97 & .96 & .05 \\
\hline $\begin{array}{l}\text { 2. Four-factor model: emotional exhaustion and psychological withdrawal } \\
\text { loaded on the same factor }\end{array}$ & $482.20^{* *}(129)$ & $240.01^{* *}(4)$ & .10 & .90 & .88 & .11 \\
\hline $\begin{array}{l}\text { 3. Four-factor model: emotional exhaustion and work goal attainment loaded on } \\
\text { the same factor }\end{array}$ & $1397.80^{* *}(129)$ & $1154.89^{* * *}(4)$ & .19 & .64 & .57 & .19 \\
\hline $\begin{array}{l}\text { 4. Four-factor model: emotional exhaustion and personal initiative loaded on } \\
\text { the same factor }\end{array}$ & $822.99^{* *}(129)$ & $580.08^{* *}(4)$ & .14 & .80 & .77 & .16 \\
\hline 5. One-factor model: all the items were combined into one factor & $2088.45^{* *}(135)$ & $1845.54^{* * *}(10)$ & .23 & .44 & .37 & .18 \\
\hline $\begin{array}{l}\text { 6. Six-factor model: one uncorrelated latent method factor was added to the } \\
\text { baseline five-factor model }\end{array}$ & $242.17^{* *}(123)$ & $.74(2)$ & .06 & .97 & .96 & .05 \\
\hline
\end{tabular}

$N=282 .{ }^{* *} p<.01$ (two-tailed tests). ${ }^{\text {a }}$ Five factors include: self-partner disagreements over COVID-19 prevention measures, emotional exhaustion, psychological withdrawal, work goal attainment, and personal initiative. RMSEA = root-mean-square error of approximation; $\mathrm{CFI}=\mathrm{com}$ parative fit index, TLI $=$ Tucker-Lewis index, SRMR = standardized root-mean-square residual. 
Table 2 Demographics and correlations

\begin{tabular}{|c|c|c|c|c|c|c|c|c|c|c|c|c|}
\hline Variables & Mean & $S D$ & 1 & 2 & 3 & 4 & 5 & 6 & 7 & 8 & 9 & 10 \\
\hline $\begin{array}{l}\text { 1. Perceived self-partner disagreements over } \\
\text { COVID-19 prevention measures }\end{array}$ & 1.90 & .74 & .79 & & & & & & & & & \\
\hline 2. Marital status & .50 & .50 & -.05 & & & & & & & & & \\
\hline 3. Reduction in identification with the partner & -.20 & 1.45 & $.10^{+}$ & -.06 & & & & & & & & \\
\hline 4. Emotional exhaustion & 3.70 & 1.51 & -.07 & -.09 & $.12^{+}$ & .91 & & & & & & \\
\hline 5. Psychological withdrawal & 3.56 & 1.09 & $.17^{* *}$ & -.06 & -.02 & $.28^{* *}$ & .78 & & & & & \\
\hline 6. Work goal attainment & 4.72 & 1.23 & $-.18^{* *}$ & -.00 & .02 & $-.24^{* *}$ & $-.42^{* *}$ & .94 & & & & \\
\hline 7. Personal initiative & 4.79 & 1.07 & $-.21^{* *}$ & .06 & -.00 & $-.18^{* *}$ & $-.38^{* *}$ & $.55^{* *}$ & .90 & & & \\
\hline 8. Age & 34.13 & 8.39 & -.02 & $.40^{* *}$ & -.06 & $-.23^{* *}$ & $-.12^{*}$ & .08 & .09 & & & \\
\hline 9. Gender & .42 & .50 & .07 & $.12^{+}$ & .07 & $-.23^{* *}$ & -.01 & .02 & .07 & $.12^{*}$ & & \\
\hline 10. Relationship duration with the partner & 8.84 & 7.27 & -.04 & $.54^{* *}$ & -.06 & $-.12^{*}$ & -.02 & .04 & .07 & $.63^{* *}$ & .03 & \\
\hline 11. Identification before COVID-19 & 4.98 & 1.81 & $-.20^{* *}$ & $.17^{* *}$ & $.32^{* *}$ & -.01 & $-.10^{+}$ & $.16^{* *}$ & $.12^{*}$ & -.09 & $.12^{+}$ & .05 \\
\hline
\end{tabular}

$N=282$. Gender was coded with $0=$ Female and $1=$ Male. Marital status was coded with $0=$ Not married and $1=$ Married. Reliabilities were reported in diagonal (in italic and boldface).

${ }^{+} p<.10,{ }^{*} p<.05,{ }^{* *} p<.01$ (two-tailed tests)

\section{Hypotheses Testing}

Two structural models were performed. The first model, without the moderator, was performed to test Hypotheses 1, 2 , and 3. This was a fully saturated model, yielding perfect model fit. The second model added marital status as a moderator and the interaction between perceived self-partner disagreements over COVID-19 prevention measures and marital status. Grand-mean centering was performed before the interaction term was computed. This model showed good model fit: $\chi^{2}(8)=5.93, p=.66$, RMSEA $=.00, \mathrm{CFI}=$ $1.00, \mathrm{TLI}=1.04$, and SRMR $=.01$. We computed $95 \%$ biascorrected confidence intervals (CI) using the estimates from 1,000 bootstrapped samples (Shrout \& Bolger, 2002). The unstandardized and the indirect effect results are reported in Table 3 and 4 respectively.

Table 3 Unstandardized path analysis results

\begin{tabular}{|c|c|c|c|c|c|c|}
\hline \multirow{2}{*}{$\begin{array}{l}\text { Variables } \\
\text { Controls }\end{array}$} & \multicolumn{2}{|c|}{$\begin{array}{l}\text { Reduction in } \\
\text { identification with the } \\
\text { partner }\end{array}$} & \multirow[t]{2}{*}{ Emotional exhaustion } & \multirow[t]{2}{*}{$\begin{array}{l}\text { Psychological } \\
\text { withdrawal }\end{array}$} & \multirow[t]{2}{*}{$\begin{array}{l}\text { Work goal } \\
\text { attainment }\end{array}$} & \multirow[t]{2}{*}{$\begin{array}{l}\text { Personal } \\
\text { initiative }\end{array}$} \\
\hline & & & & & & \\
\hline Age & $.01(.01)$ & $.01(.01)$ & $-.04^{* *}(.01)$ & $-.02^{+}(.01)$ & $.01(.01)$ & $.01(.01)$ \\
\hline Gender & $.03(.17)$ & $.06(.16)$ & $-.60^{* *}(.17)$ & $.15(.13)$ & $-.13(.15)$ & $.06(.13)$ \\
\hline Relationship duration with the partner & $-.02(.01)$ & $-.01(.02)$ & $.01(.02)$ & $.02(.01)$ & $-.01(.01)$ & $.00(.01)$ \\
\hline Identification before COVID-19 & $.29^{* *}(.05)$ & $.30^{* *}(.05)$ & $-.07(.05)$ & $-.04(.04)$ & $.09^{*}(.04)$ & $.04(.04)$ \\
\hline \multicolumn{7}{|l|}{ Main effects } \\
\hline $\begin{array}{l}\text { Perceived self-partner disagreements over COVID- } \\
19 \text { prevention measures }\end{array}$ & $.33^{* *}(.11)$ & $.32^{* * *}(.11)$ & $-.19(.12)$ & $.26^{* *}(.09)$ & $-.29^{* *}(.10)$ & $-.30^{* *}(.09)$ \\
\hline Marital status & & $-.31(.19)$ & & & & \\
\hline \multicolumn{7}{|l|}{ Moderating effect } \\
\hline $\begin{array}{l}\text { Perceived self-partner disagreements } \times \text { Marital } \\
\text { status }\end{array}$ & & $-.49^{*}(.22)$ & & & & \\
\hline \multicolumn{7}{|l|}{ Mediating effects } \\
\hline Reduction in identification with the partner & & & $.16^{*}(.06)$ & $-.04(.05)$ & $.03(.05)$ & $.01(.05)$ \\
\hline Emotional exhaustion & & & & $.21^{* *}(.04)$ & $-.21^{* *}(.05)$ & $-.13^{* *}(.04)$ \\
\hline Residual variance & 1.80 & 1.75 & 2.00 & 1.03 & 1.33 & 1.03 \\
\hline $\mathrm{R}^{2}$ & $.14^{* *}$ & $.16^{* *}$ & $.12^{* *}$ & $.13^{* *}$ & $.12^{* *}$ & $.09^{* *}$ \\
\hline
\end{tabular}

$N=282$. The standard errors were included in parentheses. $\mathrm{R}^{2}$ was computed from the formula of (1-residual variance)/total variance.

${ }^{+} p<.10,{ }^{*} p<.05,{ }^{* *} p<.01$ (two-tailed tests). 
Table 4 Indirect relationships and conditional indirect relationships

\begin{tabular}{|c|c|c|}
\hline Relationships & Indirect effects & $95 \% \mathrm{CI}$ \\
\hline $\begin{array}{l}\text { Perceived self-partner disagreements over COVID-19 prevention measures } \rightarrow \text { Reduction in identification } \rightarrow \\
\text { Emotional exhaustion }(H 2)\end{array}$ & .053 & {$[.007, .145]$} \\
\hline $\begin{array}{l}\text { Perceived self-partner disagreements over COVID-19 prevention measures } \rightarrow \text { Reduction in } \\
\text { identification } \rightarrow \text { Emotional exhaustion } \rightarrow \text { Psychological withdrawal }\end{array}$ & Indirect effects & $95 \% \mathrm{CI}$ \\
\hline Indirect relationship $(\mathrm{H} 3 a)$ & .011 & {$[.002, .035]$} \\
\hline \multicolumn{3}{|l|}{ Conditional Indirect Relationships (H5a) } \\
\hline Not married & .017 & {$[.003, .047]$} \\
\hline Married & .002 & {$[-.008, .022]$} \\
\hline Difference & -.015 & {$[-.048,-.001]$} \\
\hline $\begin{array}{l}\text { Perceived self-partner disagreements over COVID-19 prevention measures } \rightarrow \text { Reduction in } \\
\text { identification } \rightarrow \text { Emotional exhaustion } \rightarrow \text { Work goal attainment }\end{array}$ & Indirect effects & $95 \% \mathrm{CI}$ \\
\hline Indirect relationship $(\mathrm{H} 3 \mathrm{~b})$ & -.011 & {$[-.036,-.002]$} \\
\hline \multicolumn{3}{|l|}{ Conditional Indirect Relationships (H5b) } \\
\hline Not married & -.017 & {$[-.049,-.004]$} \\
\hline Married & -.002 & {$[-.024, .007]$} \\
\hline Difference & .015 & {$[.001, .046]$} \\
\hline $\begin{array}{l}\text { Perceived self-partner disagreements over COVID-19 prevention measures } \rightarrow \text { Reduction in } \\
\text { identification } \rightarrow \text { Emotional exhaustion } \rightarrow \text { Personal initiative }\end{array}$ & Indirect effects & $95 \% \mathrm{CI}$ \\
\hline Indirect relationship $(\mathrm{H} 3 \mathrm{c})$ & -.007 & {$[-.026,-.001]$} \\
\hline \multicolumn{3}{|l|}{ Conditional Indirect Relationships (H5c) } \\
\hline Not married & -.011 & {$[-.032,-.002]$} \\
\hline Married & -.001 & {$[-.016, .004]$} \\
\hline Difference & .009 & {$[.000, .030]$} \\
\hline
\end{tabular}

$95 \%$ confidence intervals $(\mathrm{CI})$ were computed from analysis with bootstrap $=1000$.

Table 3 shows that the relationship between perceived self-partner disagreements over COVID-19 prevention measures and reduction in identification with the partner was significantly positive $(B=.33$, s.e. $=.11, p=.003)$. Thus, Hypothesis 1 was supported. Table 4 shows that the indirect effects of perceived self-partner disagreements over COVID-19 prevention measures on emotional exhaustion through reduction in identification with the partner was significantly positive, with estimate $=.053$ and $95 \%$ CI $[.007, .145]$. Thus, Hypothesis 2 was supported. Table 4 also shows that the sequential indirect relationships between perceived self-partner disagreements over COVID-19 prevention measures and (a) psychological withdrawal, (b) work goal attainment, and (c) personal initiative through reduction in identification with the partner and emotional exhaustion were all significant, with estimate $=.011$ and $95 \%$ CI $[.002, .035]$ for psychological withdrawal; estimate $=-.011$ and $95 \% \mathrm{CI}$ $[-.036,-.002]$ for work goal attainment; and estimate $=$ $-.007,95 \%$ CI [-.026, -.001] for personal initiative. Therefore, Hypothesis 3 was supported.

Table 3 shows that the effect of interaction between perceived self-partner disagreements over COVID-19 prevention measures and marital status on reduction in identification with the partner was significant $(B=-.49$, s.e. $=$ $.22, p=.024)$. As shown in Fig. 2, the relationship between perceived self-partner disagreements over COVID-19 prevention measures and reduction in identification with the partner was positive and significant when participants were not married with their partner $(B=.56$, s.e. $=.15, p<.001)$ but not significant when participants were married with their partner $(B=.07$, s.e. $=.16, p=.64)$. Thus, Hypothesis 4 was supported.

Table 4 also shows that the indirect effects of perceived self-partner disagreements over COVID-19 prevention measures on psychological withdrawal through reduction in identification with the partner and emotional exhaustion was significant when participants were not married with their partner, with estimate $=$ .017 and $95 \%$ CI [.003, .047], but not significant when participants were married with their partner, with estimate $=.002$ and 95\% CI [-.008, .022]. The difference between the two effects was significant, with estimate $=-.015$ and $95 \%$ CI $[-.048,-.001]$. The indirect effect of perceived self-partner disagreements over COVID-19 prevention measures on work goal attainment through 
Fig. 2 Interactive effect of perceived self-partner disagreements over COVID-19 prevention measures and marital status on reduction in identification with the partner

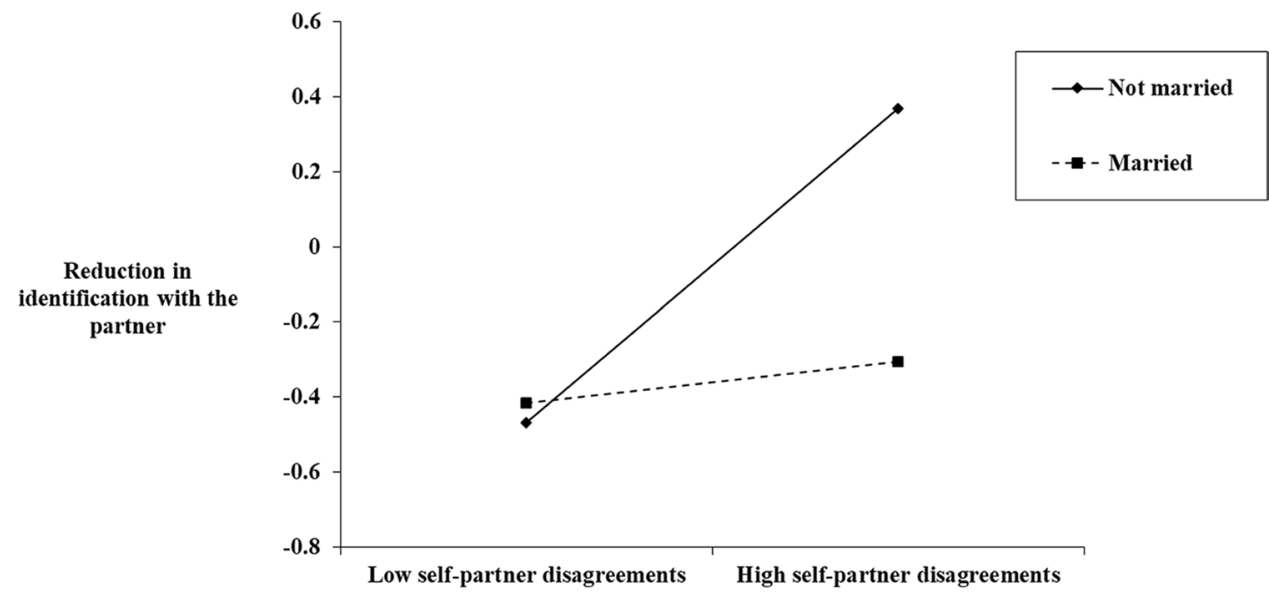

reduction in identification with the partner and emotional exhaustion was significant when participants were not married with their partner, with estimate $=-.017$ and $95 \%$ CI [-.049, -.004], but not significant when they were married with their partner, with estimate $=-.002$ and $95 \%$ CI [-.024, .007]. The difference between the two effects was significant, with estimate $=.015$ and 95\% CI [.001, .046]. The indirect effect of perceived self-partner disagreement over COVID-19 prevention measures on personal initiative through reduction in identification with the partner and emotional exhaustion was significant when participants were not married with their partner, with estimate $=-.011$ and $95 \% \mathrm{CI}$ [-.032. -.002], but not significant when they were married with their partner, with estimate $=-.001,95 \% \mathrm{CI}$ $[-.016, .004]$. The difference between the two effects was significant, with estimate $=.009$ and $95 \%$ CI [.000, .030]. Therefore, Hypothesis 5 was supported.

\section{Discussion}

Everyone's life and work have changed a lot because of the COVID-19 pandemic. Many start to work from home, feeling the increasingly blurred boundary between life and work. Meanwhile, our society has taken many prevention measures intending to reduce the spread of the epidemic. Because these prevention measures restrict people's freedom, people do not agree to and implement them unanimously. Drawing upon the interpersonal self-regulation perspective, we predicted that when partners disagreed over the COVID-19 prevention measures, they may see such disagreement as an indicator of their fundamental value differences, experienced identification reduction with the partner, experienced emotional exhaustion, and displayed negative work behaviors when they worked from home. We also theorized that these negative effects of perceived disagreements with partners over the COVID-19 prevention measures would be weaker for married partners. A two-wave study provides support for our theoretical model.

\section{Theoretical Implications}

Our research makes important theoretical contributions to the literature. First, we contribute to the crisis literature by explaining how family experiences in times of COVID-19 crisis influenced people's work outcomes from an interpersonal self-regulation perspective. Existing research has rarely incorporated non-work crisis events into the discussion of the work-family interface (Eby et al., 2016). Our results suggest that a family's experience in times of crisis not only affected relationships among family members (manifested as a reduction in identification with the partner) but also further affected individuals' work performance. Different responses toward COVID-19 prevention measures reflected differences in values and political ideologies between partners (Conway III et al., 2021) and thus had the effect of stimulating the appearance of deep-seated differences (Van Bavel et al., 2020) that worsened the interpersonal relationships within the family. The deterioration of the self-partner relationship further divided the relational unit between partners, exhausted individuals' regulatory resources, and undermined their work outcomes. Our results partly explain why relationship conflict and dissolution within family often increase in times of crisis (Dew et al., 2012; Gimbel \& Booth, 1994) despite relational support from family members being 
needed at these times to help build resilience in the family and work domains (Caruana, 2010; Eby et al., 2016; Van Daalen et al., 2006; Walsh, 2016). It is important to consider whether family members can deal with the crisis unanimously.

Second, this study extends the literature on working from home by highlighting the detrimental effects of the crisis spilling over from the family domain to the work domain. Although previous literature has mainly depicted a positive picture of work-from-home practices (Bloom et al., 2015; Gajendran \& Harrison, 2007), some research suggests that working from home may introduce or heighten family-towork interference (Golden et al., 2006). Our study seized the opportunity provided by the prevalence of working from home during the COVID-19 pandemic to explore explanations for this increased interference. Specifically, we identified perceived self-partner disagreement over COVID-19 prevention measures as an important factor in negatively shaping work outcomes of employees who worked from home.

Third, our study contributes to the literature on familyto-work interference by taking a process view on how the interference occurs. Most work-family research has asked participants to directly report the extent of interference (e.g., "Tension and anxiety from my family life often weakens my ability to do my job"; Wang et al., 2010; Liu et al., 2015). Such an approach is useful for identifying whether an individual perceives family-to-work interference but does not enlighten us on how this interference occurs. Built on the interpersonal self-regulation perspective, our study unpacked the underlying processes by indicating that perceived self-partner disagreements over COVID-19 prevention measures triggered a process of family-work interference by sequentially reducing the identification between partners and exhausting individuals.

\section{Practical Implications}

The results of our study imply that it is important for people and their partners to develop shared beliefs during time of stress and uncertainty (Prime et al., 2020). Due to the COVID-19 crisis, people are spending more time with their families while working from home. Nevertheless, crisis situations may become a salient context for deep-seated differences between partners to emerge. Individuals - especially those who are not married with their partners-should be alert to the differences in their crisis prevention attitudes to that of their partners, because managing family disagreement is critical not only for the relationship with their partners, but also for their own work outcomes.
Many organizations, such as Google, Uber, Airbnb, Zillow, Twitter, adopted work-from-home policy as the coronavirus pandemic wears on and many of these organizations (e.g., Twitter) even announced that employees can work from home indefinitely. However, our results suggest that working from home may not be equally effective for all employees. Organizations need to recognize that, although employees may support work from home policies, family-to-work interference may undermine the effectiveness of the practice. In light of these findings, organizations could consider providing workshops or training in communication skills for employees. Organizations should be able to yield real benefits in employees' performance through improvements in the relational self-regulation unit between employees and their partners within the family domain.

\section{Limitations and Future Directions}

Our research has several limitations that may inspire interesting future research. First, although causality cannot be conclusively established from our survey data, we took efforts to make our model estimations reliable (Rohrer, 2018). We tested our measurement model and found our data fit the baseline five-factor model well, which indicates that measurement error only has limited effect on our model. We also believe the data were appropriately modeled, as our theoretical framework interpersonal self-regulation perspective suggests, relational factors deplete self-regulatory resources and thus worsen personal goal achievements. Moreover, we considered potential confounders and controlled for age, gender, relationship duration, and identification with the partner before the COVID-19 outbreak to eliminate their possible influences on our modeled process of familyto-work interference.

Second, all studied variables were measured from the same source due to data collection constrains during the epidemic. To eliminate the threat of common-method factor to our results, we attempted to minimize this bias by following the procedures recommended by Podsakoff et al. (2003), such as creating time separations between study variables, using different measurement anchors, and directly assessing the threat through CFA procedures. Furthermore, the results of the interactions cannot be explained by the common method factor because correlated errors cannot create spurious interactions (Schmitt, 1994). Nevertheless, future research may consider using different sources of information, including partner-rated self-values and supervisor- or colleaguerated work outcomes. 
Third, the generalizability of the current findings should be further tested. COVID-19 prevention measures are related to the social norms and cultural values of the countries in which they are implemented. The U.K. and the U.S. are characterized as having weak norms and loose cultures (Gelfand et al., 2011). Therefore, we were more likely to observe perceived disagreements between partners over prioritizing constraints or freedom in our sample. Future research should examine whether our results can be generalized to people in countries with strong norms and a tight culture. For example, in a tight culture, even when individuals are against the imposition of COVID-19 prevention measures, strong social norms may pressure them to obey. In this situation, perceived disagreements between partners may be less salient. Such cultural differences could also potentially relate to political differences which have implications about individuals' attitudes toward prevention measures. Loose cultures allow individuals to express their different opinions and thus it should be easier to find disagreements between partners over prioritizing constraints or freedom in loose cultures; tight cultures emphasizes individuals in the culture sharing the same belief, thus it should be easier to observe consensus between partners over prioritizing constraints or freedom in tight cultures. Therefore, researchers could include such cultural differences in the model and examine their role in shaping family relationships and individuals' work outcomes.

\section{Conclusions}

The COVID-19 allows us to examine how family prevention experiences influence employees who work from home, a research topic that potentially sheds lights on whether the practice of work from home works equally well for all the employees. Our research suggests that organizations should be alert that for employees with partners, especially when they are not married with their partners, their work performance at home is likely to be negatively associated with their deep disagreements with the partner (e.g., how to deal with COVID-19). With this knowledge, organizations and employees can take active strategies to reduce this negative impact and facilitate the effectiveness of work from home practice.

\section{Appendix A}

\section{Measures of perceived self-partner disagreements over COVID-19 prevention measures}

To what extent do you think that you and your partner share the same opinions toward each of the following statements about COVID-19 prevention measures with $1=$ we have low consensus, $7=$ we have high consensus:

"To control the spread of COVID-19 ..."

1. people should stay home and avoid going outside as much as possible.

2. companies/organizations should ask employees to work from home.

3. people should practice social distancing (e.g., keep physical distance) between each other.

4. everyone should wear a mask when going out.

5. people should follow orders of mandated quarantines (e.g., anyone who travelled from a severely affected COVID-19 area must stay home or stay in government assigned hotels for 14 days before going out).

6. it is necessary to cancel gathering activities.

7. everyone should yield some rights to allow government to track their locations and movement (e.g., by installing certain phone apps to allow so).

8. everyone should give up some freedom and submit to authority and central control.

9. everyone should give up some personal space and convenience to be cooperative with government orders.

Notes. The consensus was reverse coded for perceived self-partner disagreements over COVID-19 prevention measures

\section{Appendix B}

\section{Measures of identification with the partner (identification reduction was computed from Before COVID-19 identification - After COVID-19 identification)}

Below are eight pictures that represent different feelings of connection that you might have with your partner. Before the outbreak of COVID-19 (After the outbreak of COVID19), which of the following picture represents your feelings of connection that you might have with your partner? 
A

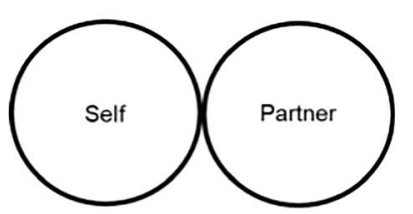

$E$

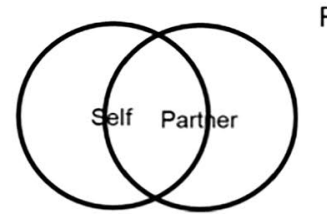

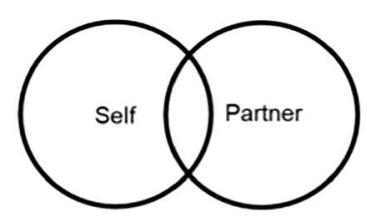

$\mathrm{F}$

G
C

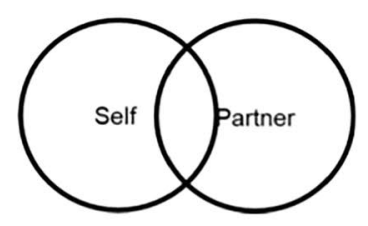

D

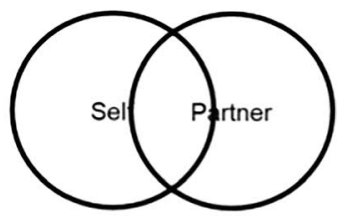

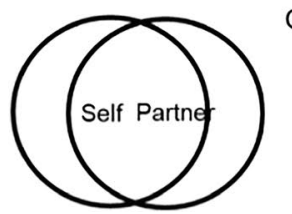

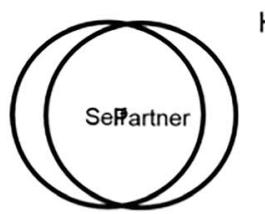

$\mathrm{H}$

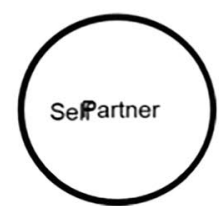

Funding This research was supported by the scholarship from the National Natural Science Foundation of China (71902141, 71902143, and 72002157), Shanghai Chenguang Program (20CG28), and Shanghai Pujiang Program (2019PJC101).

Data availability The datasets generated during and/or analysed during the current study are available via Open Science Framework website, https://osf.io/hu8kz/?view_only=bb62a11639d54d56ba66ad32fe2cec dd.

\section{Declarations}

Conflict of interest The authors declare that there is no conflict of interest.

Ethics approval Approval was obtained from the ethics committee of Tongji University. The procedures used in this study adhere to the tenets of the Declaration of Helsinki.

Informed Consent Informed consent was obtained from all individual participants included in the study.

\section{References}

Adams, J. M., \& Jones, W. H. (1997). The conceptualization of marital commitment: An integrative analysis. Journal of Personality and Social Psychology, 72, 1177-1196. https://doi.org/10.1037/ 0022-3514.72.5.1177

Allen, T. D., Johnson, R. C., Kiburz, K. M., \& Shockley, K. M. (2013). Work-family conflict and flexible work arrangements: Deconstructing flexibility. Personnel psychology, 66, 345-376. https:// doi.org/10.1111/peps.12012

Amato, P. R., \& Rogers, S. J. (1997). A longitudinal study of marital problems and subsequent divorce. Journal of Marriage and the Family, 59, 612-624 https://www.jstor.org/stable/353949

Amstad, F. T., Meier, L. L., Fasel, U., Elfering, A., \& Semmer, N. K. (2011). A meta-analysis of work-family conflict and various outcomes with a special emphasis on cross-domain versus matchingdomain relations. Journal of Occupational Health Psychology, 16, 151-169. https://doi.org/10.1037/a0022170

Aron, A., Aron, E., \& Smollan, D. (1992). Inclusion of Other in the Self Scale and the structure of interpersonal closeness. Journal of
Personality and Social Psychology, 63, 596-612. https://doi.org/ 10.1037/0022-3514.63.4.596

Baert, S., Lippens, L., Moens, E., Sterkens, P., \& Weytjens, J. (2020). How do we think the COVID-19 crisis will affect our careers (if any remain)? Institute of Labor Economics (IZA) Discussion Paper, 13164

Barley, S. R., Bechky, B. A., \& Milliken, F. J. (2017). The changing nature of work: Careers, identities, and work lives in the 21 st century. Academy of Management Discoveries, 3, 111-115. https:// doi.org/10.5465/amd.2017.0034

Beigi, M., Shirmohammadi, M., \& Stewart, J. (2018). Flexible work arrangements and work-family conflict: A metasynthesis of qualitative studies among academics. Human Resource Development Review, 17, 314-336. https://doi.org/10.1177/1534484318787628

Beigi, M., Wang, J., \& Arthur, M. B. (2017). Work-family interface in the context of career success: A qualitative inquiry. Human Relations, 70, 1091-1114. https://doi.org/10.1177/0018726717691339

Bernstein, R. E., Laurent, S. M., \& Laurent, H. K. (2016). Much ado about your thing: Conflict structure moderates the effect of attachment anxiety on postconflict perceived self-partner overlap. Couple and Family Psychology, 5, 168-179. https://doi.org/10.1037/ cfp0000064

Bloom, N., Liang, J., Roberts, J., \& Ying, Z. J. (2015). Does working from home work? Evidence from a Chinese experiment. The Quarterly Journal of Economics, 130, 165-218. https://doi.org/ 10.1093/qje/qju032

Browne, D. T., Plamondon, A., Prime, H., Puente-Duran, S., \& Wade, M. (2015). Cumulative risk and developmental health: an argument for the importance of a family-wide science. Wiley Interdisciplinary Reviews: Cognitive Science, 6, 397-407. https://doi. org/10.1002/wcs. 1349

Chi, S. C. S., \& Liang, S. G. (2013). When do subordinates' emotionregulation strategies matter? Abusive supervision, subordinates' emotional exhaustion, and work withdrawal. The Leadership Quarterly, 24, 125-137. https://doi.org/10.1016/j.leaqua.2012. 08.006

Cho, E. (2020). Examining boundaries to understand the impact of COVID-19 on vocational behaviors. Journal of Vocational Behavior, 119, 103437. https://doi.org/10.1016/j.jvb.2020.103437

Cole, M. S., Bernerth, J. B., Walter, F., \& Holt, D. T. (2010). Organizational justice and individuals' withdrawal: Unlocking the influence of emotional exhaustion. Journal of Management Studies, 47, 367-390. https://doi.org/10.1111/j.1467-6486.2009.00864.x

Conway III, L. G., Woodard, S. R., Zubrod, A., \& Chan, L. (2021). Why are conservatives less concerned about the coronavirus 
(COVID-19) than liberals? Comparing political, experiential, and partisan messaging explanations. Personality and Individual Differences, 183, 111124. https://doi.org/10.1016/j.paid. 2021.111124

Cropanzano, R., Rupp, D. E., \& Byrne, Z. S. (2003). The relationship of emotional exhaustion to work attitudes, job performance, and organizational citizenship behaviors. Journal of Applied Psychology, 88, 160-169. https://doi.org/10.1037/0021-9010.88.1.160

Cunningham, C. J., \& De La Rosa, G. M. (2008). The interactive effects of proactive personality and work-family interference on wellbeing. Journal of Occupational Health Psychology, 13, 271-282. https://doi.org/10.1037/1076-8998.13.3.271

Dew, J., Britt, S., \& Huston, S. (2012). Examining the relationship between financial issues and divorce. Family Relations, 61, 615628. https://doi.org/10.1111/j.1741-3729.2012.00715.x

Dubey, A. D., \& Tripathi, S. (2020). Analysing the sentiments towards work-from-home experience during covid-19 pandemic. Journal of Innovation Management, 8, 13-19. https://doi.org/10.24840/ 2183-0606_008.001_0003

Duffy, C. (2020). Big tech firms ramp up remote working orders to prevent coronavirus spread. CNN. Retrieved from https://edition. cnn.com/2020/03/10/tech/google-work-from-home-coronavirus/ index.html.

Duvall, E. M., \& Hill, R. (1945). When you marry. D. C. Heath and Co.

Eby, L. T., Mitchell, M., \& Zimmerman, L. (2016). Work and family in times of crisis. In T. Allen \& L. Eby (Eds.), The Oxford Handbook of Work and Family (pp. 417-430). Oxford Press.

Elizabeth, V. (2000). Cohabitation, marriage and the unruly consequences of difference. Gender \& Society, 14, 87-110. https://doi. org/10.1177/089124300014001006

Feeney, B. C. (2007). The dependency paradox in close relationships: Accepting dependence promotes independence. Journal of Personality and Social Psychology, 92, 268-285. https://doi.org/10. 1037/0022-3514.92.2.268

Finkel, E. J., \& Fitzsimons, G. M. (2011). The effects of social relationships on self-regulation. In K. D. Vohs \& R. F. Baumeister (Eds.), Handbook of self-regulation: Research, theory, and applications (2nd ed., pp. 390-406). Guilford Press.

Finkel, E. J., Fitzsimons, G. M., \& vanDellen, M. R. (2016). Selfregulation as a transactive process: Reconceptualizing the unit of analysis for goal setting, pursuit, and outcomes. In K. D. Vohs \& R. F. Baumeister (Eds.), Handbook of self-regulation: Research, theory, and applications (3rd ed., pp. 264-282). Guilford.

Finkel, E. J., Campbell, W. K., Brunell, A. B., Dalton, A. N., Chartrand, T. L., \& Scarbeck, S. J. (2006). High-maintenance interaction: Inefficient social coordination impairs self-regulation. Journal of Personality and Social Psychology, 91, 456-475. https://doi.org/ 10.1037/0022-3514.91.3.456

Finkel, E. J., Simpson, J. A., \& Eastwick, P. W. (2017). The psychology of close relationships: Fourteen core principles. Annual Review of Psychology, 68, 383-411. https://doi.org/10.1146/annur ev-psych-010416-044038

Fitzsimons, G. M., \& Finkel, E. J. (2010). Interpersonal influences on self-regulation. Current Directions in Psychological Science, 19, 101-105. https://doi.org/10.1177/0963721410364499

Fitzsimons, G. M., Finkel, E. J., \& Vandellen, M. R. (2015). Transactive goal dynamics. Psychological Review, 122, 648-673. https:// doi.org/10.1037/a0039654

Frese, M., \& Fay, D. (2001). Personal initiative: An active performance concept for work in the 21st century. Research in Organizational Behavior, 23, 133-187. https://doi.org/10.1016/S0191-3085(01) 23005-6

Frese, M., Fay, D., Hilburger, T., Leng, K., \& Tag, A. (1997). The concept of personal initiative: Operationalization, reliability and validity in two German samples. Journal of Occupational and
Organizational Psychology, 70, 139-161. https://doi.org/10. 1111/j.2044-8325.1997.tb00639.x

Gajendran, R. S., \& Harrison, D. A. (2007). The good, the bad, and the unknown about telecommuting: Meta-analysis of psychological mediators and individual consequences. Journal of Applied Psychology, 92, 1524-1541. https://doi.org/10.1037/0021-9010. 92.6.1524

Gelfand, M. J., Raver, J. L., Nishii, L., Leslie, L. M., Lun, J., Lim, B. C., et al. (2011). Differences between tight and loose cultures: A 33-nation study. Science, 332, 1100-1104. https://doi.org/10. 1126/science. 1197754

Gimbel, C., \& Booth, A. (1994). Why does military combat experience adversely affect marital relations? Journal of Marriage and the Family, 56, 691-703. https://doi.org/10.2307/352879

Golden, T. D., Veiga, J. F., \& Simsek, Z. (2006). Telecommuting's differential impact on work-family conflict: Is there no place like home? Journal of Applied Psychology, 91, 1340-1350. https:// doi.org/10.1037/0021-9010.91.6.1340

Greguras, G. J., \& Diefendorff, J. M. (2010). Why does proactive personality predict employee life satisfaction and work behaviors? A field investigation of the mediating role of the self-concordance model. Personnel Psychology, 63, 539-560. https://doi.org/10. 1111/j.1744-6570.2010.01180.x

Halevy, N., Chou, E. Y., \& Galinsky, A. D. (2012). Exhausting or exhilarating? Conflict as threat to interests, relationships and identities. Journal of Experimental Social Psychology, 48, 530-537. https://doi.org/10.1016/j.jesp.2011.11.004

Jung, E., \& Hecht, M. L. (2004). Elaborating the communication theory of identity: Identity gaps and communication outcomes. Cотmunication Quarterly, 52, 265-283. https://doi.org/10.1080/01463 370409370197

Kramer, A., \& Kramer, K. Z. (2020). The potential impact of the Covid-19 pandemic on occupational status, work from home, and occupational mobility. Journal of Vocational Behavior, 119, 103442. https://doi.org/10.1016/j.jvb.2020.103442

Lehman, W. E., \& Simpson, D. D. (1992). Employee substance use and on-the-job behaviors. Journal of Applied Psychology, 77, 309-321. https://doi.org/10.1037/0021-9010.77.3.309

Little, T. D., Cunningham, W. A., Shahar, G., \& Widaman, K. F. (2002). To parcel or not to parcel: Exploring the question, weighing the merits. Structural Equation Modeling, 9, 151-173. https:// doi.org/10.1207/S15328007SEM0902_1

Liu, Y., Wang, M., Chang, C. H., Shi, J., Zhou, L., \& Shao, R. (2015) Work-family conflict, emotional exhaustion, and displaced aggression toward others: The moderating roles of workplace interpersonal conflict and perceived managerial family support. Journal of Applied Psychology, 100, 793-808. https://doi.org/10. 1037/a0038387

MacDermid Wadsworth, S. M. (2010). Family risk and resilience in the context of war and terrorism. Journal of Marriage and Family, 72, 537-556. https://doi.org/10.1111/j.1741-3737.2010.00717.x

Milyavskaya, M., \& Inzlicht, M. (2017). What's so great about selfcontrol? Examining the importance of effortful self-control and temptation in predicting real-life depletion and goal attainment. Social Psychological and Personality Science, 8, 603-611. https:// doi.org/10.1177/1948550616679237

Muraven, M. R., \& Baumeister, R. F. (2000). Self-regulation and depletion of limited resources: Does self-control resemble a muscle? Psychological Bulletin, 126, 247-259. https://doi.org/10.1037/ 0033-2909.126.2.247

Neppl, T. K., Senia, J. M., \& Donnellan, M. B. (2016). Effects of economic hardship: Testing the family stress model over time. Journal of Family Psychology, 30, 12-21. https://doi.org/10.1037/ fam0000168

Pleck, J. H. (1977). The work-family role system. Social Problems, 24 , 417-427. https://doi.org/10.2307/800135 
Podsakoff, P. M., MacKenzie, S. B., Lee, J. Y., \& Podsakoff, N. P. (2003). Common method biases in behavioral research: a critical review of the literature and recommended remedies. Journal of Applied Psychology, 88, 879-903. https://doi.org/10.1037/ 0021-9010.88.5.879

Prime, H., Wade, M., \& Browne, D. T. (2020). Risk and resilience in family well-being during the COVID-19 pandemic. American Psychologist., 75(5), 631-643 https://doi.org/10.1037/amp00 00660

Pugh, S. D., Groth, M., \& Hennig-Thurau, T. (2011). Willing and able to fake emotions: A closer examination of the link between emotional dissonance and employee well-being. Journal of Applied Psychology, 96, 377-390. https://doi.org/10.1037/ a0021395

Radcliffe, L. S., \& Cassell, C. (2014). Resolving couples' work-family conflicts: The complexity of decision making and the introduction of a new framework. Human Relations, 67, 793-819. https://doi. org/10.1177/0018726713506022

Riggs, S. A., \& Riggs, D. S. (2011). Risk and resilience in military families experiencing deployment: The role of the family attachment network. Journal of Family Psychology, 25, 675-687. https://doi.org/10.1037/a0025286

Rofcanin, Y., \& Anand, S. (2020). Human Relations virtual special issue: Flexible Work Practices and Work-Family Domain. Human Relations, 73, 1182-1185. https://doi.org/10.1177/0018726720 935778

Rohrer, J. M. (2018). Thinking clearly about correlations and causation: graphical causal models for observational data. Advances in Methods and Practices in Psychological Science, 1, 27-42. https:// doi.org/10.1177/2515245917745629

Schmitt, N. (1994). Method bias: The importance of theory and measurement. Journal of Organizational Behavior, 15, 393-398. https://doi.org/10.1002/job.4030150504

Schubert, T. W., \& Otten, S. (2002). Overlap of self, ingroup, and outgroup: Pictorial measures of self-categorization. Self and identity, 1,353-376. https://doi.org/10.1080/152988602760328012

Shamir, B., \& Kark, R. (2004). A single-item graphic scale for the measurement of organizational identification. Journal of Occupational and Organizational Psychology, 77, 115-123. https:// doi.org/10.1348/096317904322915946

Shrout, P. E., \& Bolger, N. (2002). Mediation in experimental and nonexperimental studies: new procedures and recommendations. Psychological Methods, 7, 422-445. https://doi.org/10.1037/1082989X.7.4.422

Skoufias, E. (2003). Economic crises and natural disasters: Coping strategies and policy implications. World Development, 31, 1087 1102. https://doi.org/10.1016/S0305-750X(03)00069-X

Sluss, D. M., \& Ashforth, B. E. (2007). Relational identity and identification: Defining ourselves through work relationships. Academy of Management Review, 32, 9-32. https://doi.org/10.5465/amr.2007. 23463672
Stanley, S. M., Markman, H. J., \& Whitton, S. W. (2002). Communication, conflict and commitment: Insights on the foundations of relationship success from a national survey. Family Process, 41, 659-675. https://doi.org/10.1111/j.1545-5300.2002.00659.x

Swann Jr., W. B., Jetten, J., Gómez, Á., Whitehouse, H., \& Bastian, B. (2012). When group membership gets personal: A theory of identity fusion. Psychological Review, 119, 441-456. https://doi. org/10.1037/a0028589

Thelwall, M., \& Thelwall, S. (2020). Retweeting for COVID-19: Consensus building, information sharing, dissent, and lockdown life. ArXiv, abs/2004.02793. http://arxiv.org/abs/2004.02793.

Tian, H., Liu, Y., Li, Y., Wu, C. H., Chen, B., Kraemer, M. U., et al. (2020). An investigation of transmission control measures during the first 50 days of the COVID-19 epidemic in China. Science, 368, 638-642. https://doi.org/10.1126/science.abb6105

Valentine, G., \& Hughes, K. (2010). Ripples in a pond: The disclosure to, and management of, problem Internet gambling with/in the family. Community, Work, \& Family, 13, 273-290. https://doi. org/10.1080/13668803.2010.488107

Van Bavel, J. J., Baicker, K., Boggio, P. S., Capraro, V., Cichocka, A., Cikara, M., et al. (2020). Using social and behavioural science to support COVID-19 pandemic response. Nature Human Behaviour, 4, 460-471. https://doi.org/10.1038/s41562-020-0884-Z

Van Daalen, G., Willemsen, T. M., \& Sanders, K. (2006). Reducing work-family conflict through different sources of social support. Journal of Vocational Behavior, 69, 462-476. https://doi.org/10. 1016/j.jvb.2006.07.005

Walsh, F. (2016). Family resilience: A developmental systems framework. European Journal of Developmental Psychology, 13, 313324. https://doi.org/10.1080/17405629.2016.1154035

Wang, M., Liu, S., Zhan, Y., \& Shi, J. (2010). Daily work-family conflict and alcohol use: Testing the cross-level moderation effects of peer drinking norms and social support. Journal of Applied Psychology, 95, 377-386. https://doi.org/10.1037/a0018138

Wang, X., Zhao, F., \& Lei, L. (2019). Partner phubbing and relationship satisfaction: Self-esteem and marital status as moderators. Current Psychology, 1-11. https://doi.org/10.1007/s12144-019-00275-0

Westman, M. (2002). Crossover of stress and strain in the family and in the workplace. In P. L. Perrewé \& D. C. Ganster (Eds.), Research in occupational stress and well-being (Vol. 2). JAI Press/ Elsevier.

World Health Organization. (2020, April). Coronavirus disease (COVID-19) advice for the public. https://www.who.int/emerg encies/diseases/novel-coronavirus-2019/advice-for-public

Zacher, H., Schmitt, A., Jimmieson, N. L., \& Rudolph, C. W. (2019). Dynamic effects of personal initiative on engagement and exhaustion: The role of mood, autonomy, and support. Journal of Organizational Behavior, 40, 38-58. https://doi.org/10.1002/job.2277

Publisher's Note Springer Nature remains neutral with regard to jurisdictional claims in published maps and institutional affiliations. 